\title{
CONSECUENCIAS PEDAGÓGICO-FORMATIVAS A PROPÓSITO DE UNA LECTURA DE UN BESO DE DICK
}

\section{Resumen}

El presente trabajo se sirve de la novela Un beso de Dick del autor -ya fallecido- Fernando Molano Vargas, para mostrar la condición precaria de una pedagogía con fines universales; especialmente cuando se trata de comprender la emergencia de las posiciones estético-corporales y erótico-sexuales de los sujetos estudiantes en el contexto de la escuela. Esa precariedad se denuncia recurriendo a instrumentos y posiciones derivadas de lo que Deborah Britzman ha llamado pedagogía queer, así como también de las incitaciones propuestas por René Schérer.

Palabras clave: Pedagogía transgresora, posiciones estético-corporales, posiciones erótico-sexuales.

\section{CONSEQÜÊNCIAS PEDAGÓGICO-FORMATIVAS A PROPÓSITO DE UMA LECTURA DE UN BESO DE DICK}

\section{Resumo}

O artigo a seguir usa o romance Un beso de Dick, do autor — já falecido_ Fernando Molano Vargas, a fim de mostrar a precária condição de uma pedagogia com pretensão universal, especialmente quando se tenta compreender a emergência das posições estético/corporal e sexual/erótico dos sujeitos. A precária condição será denunciado ao usar os instrumentos e as contribuições da pedagogia queer e os argumentos de René Schérer.

Palavras chave: Pedagogia queer, posições estética/corporal, posições sexual/erótico.

\section{PEDAGOGICAL-FORMATIVE CONSEQUENCES RELATED TO A READING OF UN BESO DE DICK}

\section{Abstract}

The following article uses the novel "Un beso de Dick" from the author -already died- Fernando Molano Vargas in order to show the precarious condition of a pedagogy with universal purposes, especially when we try to understand the emergence of esthetic-corporeal and sexual-erotic positions of school individual-students. This precarious condition is denounced by using the instruments and contributions which Deborah Britzman have named as "Queer Pedagogy" and the arguments of René Schérer.

Key words: Transgressor pedagogy, esthetic-corporeal positions, sexual-erotic positions.

\footnotetext{
Psicólogo. Magíster en Psicología. Candidato a Doctor en Educación, línea de pedagogía histórica e historia de las prácticas pedagógicas, Universidad de Antioquia. Becario de COLCIENCIAS. Miembro del "Grupo de investigación sobre formación y antropología pedagógica e histórica" -FORMAPH.

Agradezco las valiosas sugerencias hechas por Andrés Klaus Runge, Saúl Calvo Torres y Juan David Piñeres Sús. También agradezco a mi hermano más pequeño quien recordó que en la hora de la ducha en el colegio, después de las clases de Educación Física, el profesor de álgebra era el primero que buscaba lugar para apreciar el espectáculo.
}

Correo electrónico: alexdehg@yahoo.es

Artículo recibido el 14 de abril de 2009 y aprobado el 15 de mayo de 2009 
En mi mano siento la botella de mi gaseosa. La miro. Leonardo ha bebido de ella... Besársela así a Leonardo: bajarle su pantalón despacio y besársela; acariciarle con mi lengua así: mucho rato... Levanto la botella muy lento, y me entra gaseosa en la boca: como

si Leonardo se viniera en mi boca...: ¿a qué sabrá eso, Dios mío? Y me entra sensación de náusea: ¡qué estúpido: como si no lo deseara tanto!...

Fernando Molano Vargas

\section{BREVE PRESENTACIÓN DE LA NOVELA Y DEL AUTOR}

Un beso de Dick es una novela corta del autor bogotano Fernando Molano Vargas. Molano estudió Lingüística y Literatura en la Universidad Pedagógica Nacional, y Cine y Televisión en la Universidad Nacional de Colombia. Del mismo autor en 1997 la Universidad de Antioquia publicó el libro de poemas: Todas mis cosas en tus bolsillos.

Esta novela narra la historia de Felipe y Leonardo (el relato es básicamente una especie de monólogo, interrumpido por momentos en tiempo presente donde Felipe sería algo así como el "yo" de la narración): Felipe es un muchacho de 16 años que va a la escuela, es buen estudiante, fanático del fútbol (y del futbolista Iguarán), conocedor de algunos detalles sobre automóviles (su padre es mecánico y con él aprende a tomarse sus primeros tragos... también con sus amigos). Como todo muchacho de su edad comienza a hacerse preguntas sobre la vida, el amor, el sexo y las cosas que le enseñan en la institución donde estudia. Entre lo que piensa y reflexiona Felipe se hace evidente que está enamorado de Leonardo (aunque él no sabe que su amigo siente lo mismo). Felipe deja a su novia y comienza a ahondar, silenciosamente, en sus sentimientos hasta que, por fin, pueden ser puestos a prueba con los sentimientos de Leonardo. Un beso a escondidas entre los dos, no lo suficientemente oculto, evidencia una situación homoerótica en la que Felipe es marcado/identificado frente a las instancias educativas (Leonardo logra escapar). De ahí en adelante se muestra la homofobia de la educación, la injuria que la institución educativa ejerce, la dificultad del padre para comprender, las lágrimas de la madre, el silencio no acompañante de su hermano y la voluntad de Felipe por amar a Leonardo.

\section{DECIR LO QUE NO HAY QUE DECIR Y PREGUNTAR LO QUE NO HAY QUE PREGUNTAR}

¿Qué pasaría si padres, madres, maestros y maestras no supusieran, a priori, que todos los muchachos son/tienen que ser heterosexuales? ¿Qué oportunidades vitales para la existencia de muchos seres significaría descorrer las barreras que les impiden decir el nombre de aquel a quien aman? Si muchos padres, madres, maestros, maestras y demás agentes de la formación no quieren escuchar, si no se habla en los términos que ellos esperan que se hable: ¿deben los muchachos ajustar sus palabras a lo que se espera que ellos digan? o ¿habría que proponer una pedagogía que no tolere la intimidación y que fomente la corrosión de los valores usados para descalificar muchas vidas?

En adelante se retomarán brevemente algunos incidentes derivados de Comenio y Rosseau, no para indagar exhaustivamente en ellos, sino para mostrar, tal vez con ellos, que la pedagogía ha tendido a articularse como proyecto universalizante que implanta la normalidad de los muchachos como un bien social que debe procurar. Posteriormente, se plantearán los esbozos para una pedagogía transgresora (queer), a partir de la novela de Fernando Molano.

\section{El cuerpo homosexual de la pedagogía}

1679 es reconocido como el año en que, por primera vez, se publicó la Didáctica magna de Comenio, obra clave para la pedagogía, la educación y la enseñanza, puesto que, como señala Zuluaga (2007); muchos historiadores lo sitúan como el momento a partir del cual la pedagogía puede comenzar a pensarse como una disciplina autónoma. Muchas serían las consecuencias que Comenio propició para el desarrollo futuro de esta disciplina. Scheuerl (1981) sostiene que Comenio acogía los ideales estoicos, los mismos que lo llevaban a reafirmarse en el deseo de vivir de acuerdo a la naturaleza. Sin embargo, ¿qué entendía Comenio por naturaleza? Scheuerl (1981) menciona que la naturaleza, desde el autor de la Didáctica magna, involucra dos aspectos, a saber: en principio, una totalidad de la creación que posee un orden al cual deben ajustarse e integrarse las cosas; en segundo lugar, la naturaleza sería la designación que las cosas y los seres reciben por parte del Creador, designación que podría ser el modo propio y peculiar que tanto la cosa como el ser poseen por el influjo de la creación y no tendría otro fin que corresponder a ella.

Comenio acepta que todos los hombres poseen y responden a la misma naturaleza, por lo tanto, la diversidad de las disposiciones en los seres no revelaría nada más que desorden, anormalidad y falta de armonía con la creación. De algún modo Comenio establece que la diversidad en las inclinaciones del espíritu, o lo que es lo mismo, la desviación (con respecto al orden que él supone instaurado por el creador y la creación), no sería otra cosa que una manifestación de enfermedad (por utilizar una metáfora físico/corporal). Scheuerl dirá que a Comenio no le interesa la proliferación de condiciones particulares y específicas, sino la normalización del individuo

...con arreglo a la imagen de una naturaleza general del hombre. El punto de partida no es la plasticidad individual abierta a distintos estímulos e influen- 
cias, por cuya acción podrían crearse nuevas y distintas formas y destinos culturales (1981, p. 119).

Zuluaga (2007), por su parte, insistirá en la necesidad de recuperar los trabajos que los pedagogos clásicos han elaborado. Lectura que se hace relevante puesto que dichos pensadores produjeron trabajos que respondían a la necesidad de superar obstáculos (probablemente epistemológicos) referidos a una práctica del saber (en este caso, del saber pedagógico), por lo que, según ella, se trataría de servirse de la historia para observar cómo muchos de los conceptos aún vigentes tienen como condición de emergencia los problemas en el orden de las prácticas y el saber que, por ejemplo, Comenio intentó resolver. Con el sugestivo título "Otra vez Comenio", Zuluaga sostiene que es irrelevante y poco riguroso descalificar a un pensador atribuyéndole adjetivos como "idealista", "anticuado" o "metafísico"; más útil, en el caso de la pedagogía y con respecto a Comenio, será:

... trabajar en la perspectiva de valorar los conceptos que en el devenir de un conocimiento han representado momentos de impulso, de relaciones nuevas con otros conocimientos, cambios de enfoque, rupturas con planteamientos anteriores, posibilidades de respuesta para asuntos pendientes, reactivación de puntos de vista fecundos, etc. (Zuluaga, 2007, p. 102).

Ahora bien, siguiendo a Zuluaga, habría dos proposiciones -si se quiere-que importa retomar y estudiar con respecto a las múltiples consecuencias de la Didáctica magna: una en el orden del saber y otra en el orden político. En la primera se situaría la idea de Comenio referida a la pretensión de "enseñar todo a todos". En el orden político, referiríamos lo concerniente a establecer la escuela como una institución que responde al ordenamiento de la lengua materna y al método de enseñanza. Lo que podría nombrarse como efecto de un dispositivo de saber/ poder político. Si el título del trabajo de Zuluaga Otra vez Comenio, sugiere desactivar la búsqueda de sentido y reactivar una indagación histórica que sirva para relanzar los acontecimientos que posibilitaron la emergencia de un saber pedagógico; también se podría oponer a ese otra vez... un estratégico siempre Comenio, para indicar que las tentativas de unificación y universalización con respecto a un individuo que requiere educación por medio de la enseñanza (según Comenio deberán ser todos los individuos), es un deseo que no cesa y que, en el caso de la pedagogía, es un deseo continuamente reformulado. El eco de Comenio se convierte en una declaración radical de exterminio contra toda diferencia. Con Comenio nombrado explícitamente, o con Comenio ignorado por desconocimiento, la pedagogía moderna, como sostiene Wulf, siempre ha sucumbido al deseo de establecer universales y de representar las cosas tal cual son (asumiendo que lo captado por la representación se ajusta exactamente a las cosas). Al respecto:

Para la pedagogía tres son los aspectos especialmente importantes: el acceso de los individuos concretos a normas universales, la racionalización del mundo de la vida y el principio de representación (Wulf, 2004, p. 33).

Expuesto lo anterior, se dice que "siempre Comenio", porque en el programa que él pensaba para la enseñanza, la desviación de la norma natural y universal a todos los hombres era una anomalía, y por lo mismo la proliferación de alternativas vitales, o como diría Scheuerl, nuevas y distintas formas $y$ destinos culturales, no podrían constituir nada más que lo antinatural o la anticreación que desafía el orden natural. El niño de Comenio, se define como una masa informe: el lugar donde la maleabilidad-formabilidad-se ejercita, es puesta a prueba y debe ser sometida para conjurar el extravío.

Probablemente, más allá de si Comenio era o no un idealista, sus preguntas permiten hipotetizar una posición (su posición con respecto al cuerpo): el cuerpo del niño como masa informe requerida de maleabilidad. Por ello, no hay pues mucha distancia entre sus ideas y las ideas/respuestas conservadoras que actualmente se exhiben como contraargumentos a la emergencia crítica y a la crisis de representación que el cuerpo constituye para el presente de las ins- tituciones educativas, para la sociedad y para la cultura. Si se quiere, con Comenio se puede seguir insistiendo en la "necesidad" de colonizar el cuerpo del niño para evitar los extravíos a los que ese cuerpo estaría expuesto de no ajustarse a lo que la creación quiere de él. El cuerpo del niño, dicho así, sería el "lugar" donde los adultos ejercitan y ponen a prueba la formabilidad. Cuerpo que hay que derrotar, una y otra vez, porque de esa derrota depende la formación y la vigencia de los proyectos educativos.

Pedraza (1999) ha sostenido que el hogar y la escuela han sido los espacios privilegiados para educar el cuerpo. Si bien Foucault (2002a) denunció cómo el cuerpo es el objeto de todas las opresiones políticas, esas opresiones comienzan a ejercerse en los primeros ámbitos de socialización humana. El cuerpo, aquella entidad que se ha supuesto no modificada por la historia, entidad que revela la mismidad y el lugar donde se

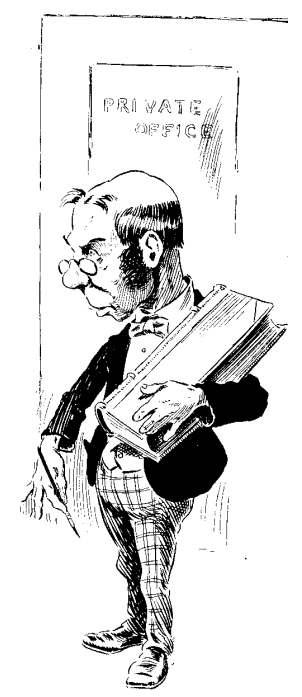

experimenta una percepción de mundo propia e irrepetible, es también lo que la pedagogía ha tornado como su objeto pedagógico (Planella, 2006). Por lo mismo, eso propio e irrepetible se convierte en lo que debe ajustarse a los dictados de lo que una sociedad anticipa. El cuerpo, se dirá, es esa apertura al mundo que comienza como una naturaleza que hay que conocer, pero también vigilar e intervenir en tanto lo que es natural pue- 
de extraviarse y causar desadaptación individual y social. Para Comenio, como ya se ha dicho, ese extraviarse es la anomalía con respecto a una naturaleza universal. Replanteando a Comenio (y siguiendo a Planella), se dirá entonces que el cuerpo es el objeto de manipulación y experimentación pedagógica que se interviene con la imperiosa necesidad de hacerlo devenir natural y universal.

Expuesto de esa manera, en el cuerpo la pedagogía encuentra y justifica un correlato positivo que garantiza su lugar dentro de la sociedad. Rousseau situaría la indefensión del niño como lo que lo haría, si se quiere, sujeto/objeto de la educación. Es esa condición prematura lo que hace que el niño carente de educación necesite a un "otro" en el proceso formativo de llegar a ser. Ahora bien, ¿la necesidad de educación justifica y condiciona una inevitable sujeción del cuerpo y la implantación de un orden socio-cultural en él1? Si dicha implantación es inaplazable ¿qué es lo que justifica las restricciones culturales que bloquean la pluralidad de imágenes que podrían devenir formativas en el excurso de un orden socio-cultural vigente? Por pluralidad se va a proponer el ejercicio de desplazar los límites de lo nombrado/nombrable y de reordenar las condiciones que hacen posible o no la circulación de otras imágenes que sean propicias para los jóvenes que no se experimentan heterocentrados, y que la institución educativa, una y otra vez, margina e injuria mediante la naturalización y universalización de la heterosexualidad2. Mientras Comenio dicta las

1 Orden socio-cultural que pareciera ser el paranoide canto a lo mismo, a lo único y a lo "verdadero," como si la sociedad y la cultura no tuvieran oportunidad de devenir más allá del culto monológico y monoteísta que entroniza, continuamente, el llamado a la marginación de lo otro/ la diferencia.

2 La heterosexualidad, más que una práctica sexual, en este trabajo se entiende como una obligación vital que se impone y se reitera mediante la afirmación: "es lo natural". La heterosexualidad como "naturaleza" es un performativo que se incardina social y culturalmente a

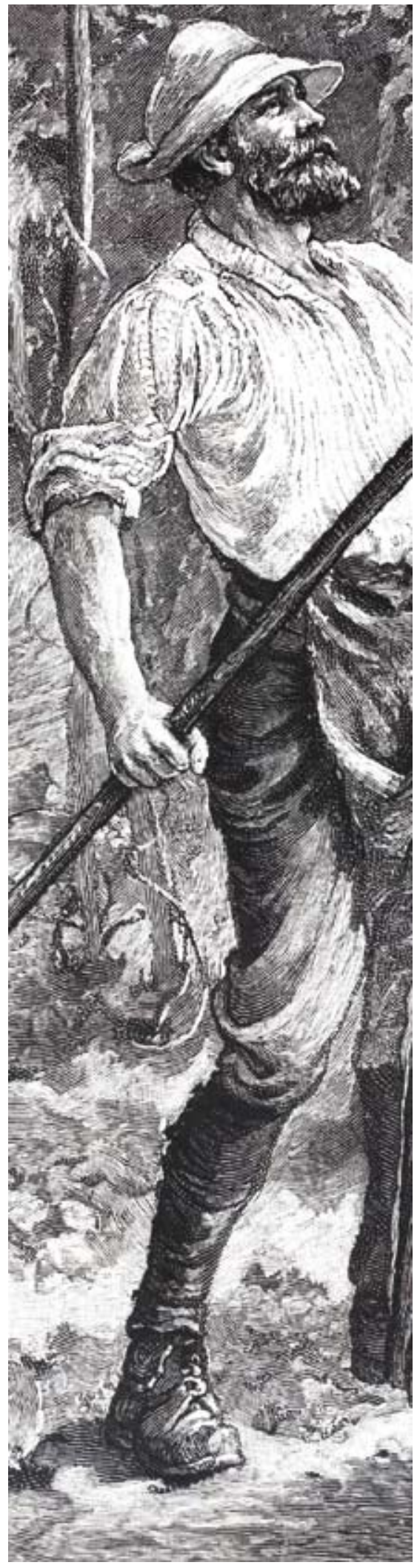

condiciones de una naturaleza universal y común, dicta también los recursos con los cuales se puede marginar y excluir, puesto que las representaciones de un orden natural estable, unívoco y universal sirven de pretexto para normalizar lo que supuestamente, por naturaleza, exige ser normalizado: ¿se entiende entonces por qué se habla de siempre Comenio?

Si la necesidad de educación sujeta/ somete a los muchachos a lo que el adulto conviene como lo que la naturaleza quiere de ellos, y si en ese privilegio del adulto Rousseau aparece para decir que no hay que ceder al capricho de los jóvenes pues hay que seguir lo que el orden natural solicita como progreso de su educación, basta entonces decir que la naturaleza es una instancia vacía: todo en ella sería suplementario en tanto lo que ella es... es lo que se establece con arreglo a universales invocados como leyes inmutables. De lo contrario, no se entendería qué es lo que se vigila, qué es lo que se cuida y qué es lo que se educa, como si se advirtiera la fragilidad de un orden natural y constante que, siempre, está en riesgo de subvertirse. Se habla aquí del cuerpo homosexual de la pedagogía como ese peligro que amenaza y que es el riesgo de la naturaleza que la pedagogía ha venido a enfrentar. Para el caso, el maestro/ maestra (adulto) constituirían, (tendrían que serlo) los garantes de la naturaleza y su función la vigilancia. El peligro del cuerpo homosexual de la pedagogía ataría al maestro/maestra a los muchachos en una relación prescrita pero sometida permanentemente a la duda y el recelo. Siempre puede ser que en el ejercicio de separar a los muchachos de sus "amistades particulares", el maestro/maestra

través de su insistente formulación. No es que los hombres, necesariamente, se enamoren de las mujeres, sino que para que la heterosexualidad pueda seguirse pensando como "naturaleza" habrá de repetirse, una y otra vez sin descanso, que la heterosexualidad "es lo natural". La "naturaleza" entonces no es lo que "Ios datos descubren", sino lo que se espera que la cultura, sin desfallecer, produzca/reproduzca por el bien de todos. 
se proponga como sustituto amoroso, así como no pocas veces se propone como sustituto materno. Schérer dirá:

¡Esa función de espiar, de vigilar en todo momento, de mantener constantemente la infancia bajo observación, ese deseo de saber, de saberlo todo! Es por ahí, solamente, por donde la relación equívoca del preceptor con el alumno halla la satisfacción, y por donde se sacia su sexualidad vergonzante (1984, p. 32).

Visto así, en el pretendido peligro del cuerpo homosexual que amenaza a los muchachos, en el peligro de ocupar ese cuerpo, la sexualidad del maestro/maestra ha de quedar atada a la intensidad de un placer difuso que se repite bajo la imperiosa compulsión que vigila/acecha. El escarceo erótico del otro, que justifica la tarea de espiar las posibles fracturas o las detenciones en el desarrollo de una sexualidad que tiene que ser libremente heterosexual, retorna como lo que hace de la sexualidad del maestro/maestra una sexualidad primitiva e infantil (en términos freudianos), pues al vigilar/ espiar a los muchachos, para cuidarlos del infantilismo y de la detención en el desarrollo que supuestamente indica el cuerpo homosexual, lo que se cifra es una sexualidad mendigante (vergonzante como diría Schérer), que debe satisfacerse con mirar, sin poder consumar el placer que se niega a sí mismo, censurando el placer de los muchachos.

Podría decirse que no en todos los casos la práctica pedagógica, concretamente la enseñanza, involucra la vigilancia como su mecanismo; no obstante, si se sigue a Foucault (2002a, p. 181), la vigilancia no sería el suplemento de la enseñanza, sino un mecanismo que le es inherente, y que multiplica su eficacia. Causa extrañeza preguntarse cómo llegó a reclamarse con tanta devoción el periódico examen del "sexo" de los muchachos como si de prevenir epidemias se tratara (¿la peste otra vez?). Seoane (2006) se pregunta por qué el sexo de los muchachos dispara las alarmas de la moral social. De hecho, con Foucault se puede sostener que por medio del examen se realiza la objetivación de los sometidos. Schérer (2005) lo expondrá de manera más drástica afirmando que la escuela, y esas paredes que también educan, se han erigido para controlar las irrupciones masturbatorias de los muchachos. Reconociendo que dicha retórica parece distante en el tiempo y más próxima a las preocupaciones de Tisot y de Rousseau, podrían replantearse las afirmaciones de Schérer y afirmar con ellas que es consustancial a la escuela la vigilancia y la prevención del cuerpo homosexual. La escuela como parte de un dispositivo mayor tendría como fin garantizar la heterosexualidad ${ }^{3}$.

Lo planteado hasta este punto no es para nada una declaración de la inocencia de los muchachos; contrariando el eco de Rousseau, las relaciones entre ellos no son inocentes, porque ninguna relación humana puede serlo. $Y$ no puede serlo porque los seres humanos no son dueños de las condiciones que los hacen devenir a la vida, al mundo y al lenguaje. Sin embargo, inocentes o no, ¿los muchachos, necesariamente, tendrían que quedar sometidos al arbitrio del adulto que vigila y reproduce un sometimiento propio que él supone eligió libremente por el bien de la sociedad?. Muchas voces al unísono podrían cantar que lo que autoriza al adulto es su madurez, pero si la madurez del adulto “... no es más que una detención del desarrollo que consiste en quedar sometido a la tutela de las instituciones y las leyes" (Schérer, 1984, p. 51), entonces la madurez a la que se quiere conducir a los muchachos, mediante el rechazo y la repulsión a ocupar un cuerpo homosexual, necesariamente significa una madurez que deplora las posibilidades

3 Basta recordar el sinnúmero de instituciones escolares que con el ánimo de celebrar el "día de la familia", utilizan frases sacadas de la Biblia para perpetuar la idea de que Dios, indudablemente, sólo podría reconocer como institución familiar a la pareja formada por un hombre y una mujer. Lo que queda claro es que, ante la ausencia del "criterio" definitivo Dios, las escuelas no están por la tarea de decir que son ellas las que no aprueban formas relacionales no heterocentradas; muy por el contrario, dirán que no son ellas sino Dios quien así lo dispone. simbólicas, corporales y estéticas que podrían ser una apertura a un mundo plural y creativo donde el destinarse no estaría subyugado con el chantaje de heterocentrarse o padecer la violencia de la exclusión/marginación.

\section{Un beso de Dick como punto de partida para interrogar a la pedagogía}

Supóngase el caso harto improbable de que algunos muchachos (no todos, ni la mayoría, para no exagerar y para no molestar a la pureza heteronormativa) se miran en la duchas mientras están desnudos o semidesnudos; supóngase que esos muchachos disfrutan lo que ven; supóngase también que tanto los muchachos que observan como los que se saben observados transforman ese instante en el instante que intensifica el placer de asistir a la escuela. O lo que es lo mismo, es el placer de ver y ser visto lo que mueve a los muchachos a estrechar una relación con la escuela. De las anteriores suposiciones se deriva un desafío para la práctica pedagógica que resiste al cuerpo homosexual, el desafío plantea: ¿Cuáles serían las intervenciones posibles por parte del maestro/maestra? ¿Denunciar las miradas? ¿Avergonzar a los muchachos mientras ese placer, ahora denunciado, se convierte en placer abyecto o placer en la abyección? ¿Denunciar que los muchachos se miran desestimula las miradas o las promueve llamando la atención sobre un punto que, a lo mejor, algunos no habían advertido? Si denunciar obliga a que los mismos muchachos vigilen la emergencia del cuerpo homosexual en/ entre ellos ¿podría verse esa demanda de vigilancia de todos y para todos como una incitación a mirar el cuerpo homosexual como una oportunidad -si se quiere maldita, pero oportunidad al fin y al cabo- para experimentar otras formas de placer?

Pásese a plantear, con la novela Un beso de Dick, incitaciones para cuestionar la pedagogía y envenenarla hasta hacerla transgresora. Fernando Molano Vargas ganó en 1992, con la novela antes citada, el Concurso Literario Cámara de Comercio de Medellín. Con la publi- 
cación del trabajo, el nombre de Fernando Molano comenzó a circular como una promesa de la literatura nacional. Su estilo fresco y sencillo para escribir, y la misma naturalidad con que emprendía la tarea de mostrar a los personajes en la extensión de una profundidad no abigarrada a manierismos y afectaciones barrocas, hacía presagiar un futuro abierto a múltiples oportunidades tanto para él como para sus lectores. Leonardo y Felipe, los héroes de Un beso de Dick (y se les llama héroes porque en ellos recae la fuerza transformadora de la acción) (Jambrina, 2000) conmovieron con un final abierto y rebosante de aporías; por un lado parecían decir que una vida impredecible y fantástica sería posible para ellos pero, por otro, también se sugería que ellos, juntos, no podrían cruzar más allá del final de la última página: Leonardo pronuncia el, por todos deseado, "te amo" dirigido a Felipe, y este le responde que ya lo sabe, tal vez, porque donde hay tanto amor sobran las frases de las telenovelas, basta con que ese amor se viva en todas partes con el sólo recuerdo de quien se ama. Concluye la novela con el tiempo que no da plazos y que recuerda que Felipe debe alejarse de ese instante que -por siempre- lo ha cobijado con Leonardo. Ante el pedido de Leonardo de que no se vaya, Felipe responde: "No me deje ir" (Molano, 1992, p 166).

Y en esa respuesta se cierra la última página del libro. Respuesta que relanza una nostalgia propia de quienes se aman pero que, en el caso de Un beso de Dick, pareciera ser el estado anímico que define a Leonardo y Felipe, puesto que lo suyo es un amor que nadie quiere, que todos reprochan y que la institución educativa en su afán formador -un marco referencial importantísimo dentro de la novela-, ha denunciado como un amor que no puede/ni debería ser; un amor que, negado por la educación, sólo puede llevar a los muchachos a practicar "porquerías" (como dirá el sacerdote de la escuela). Decir el nombre de quien se ama, si bien parecería la acción más simple y, tal vez, menos comprometida, en Un beso de Dick se transforma en una continua paradoja que arroja a Felipe hacia una incesante duda, sospecha e incertidumbre sobre quiénes lo aman, sobre qué constituye los valores de su familia, y acerca del valor moral y ético que tiene la escuela para juzgar lo que no entiende ni quiere entender. Felipe, en uno de esos momentos sencillos e ingenuos de la novela, dirá que no saben que es a Leonardo (el buen futbolista, el ávido lector de poesía y literatura... preferido por la maestra de literatura de su escuela) a quien él ama. Leonardo, el nombre que ni sus padres, ni su hermano, ni la escuela tienen como posesión (pues no lo saben y, con múltiples intimidaciones, tratarán de que lo exponga para intervenirlo también), es el referente que nombra al muchacho que Felipe ama: no lo conocen y sin embargo lo odian (dirá Felipe). Lo pueden odiar sin conocerlo, porque el odio no estaría movido por saber quién es y qué hace Leonardo sino por el hecho de saberlo el otro en un encuentro homosexual. Por todo ello, Felipe se preguntará de qué vale vivir la vida si la vida es lo que no es suyo, a la vez que su cabeza da vueltas pensando por qué es tan difícil aceptar que un muchacho se enamore de otro muchacho: "Dios ¿en dónde tienen el veneno los muchachos?" (p.111) se pregunta Felipe, retórico, intentando entender dónde reside el odio/rechazo/ repulsión que sanciona que él y Leonardo estén enamorados.

Después de todo, ellos no escogieron, el amor los escogió. Al respecto Felipe dirá:

Yo nunca dije «Voy a enamorarme de Leonardo». Yo sólo me enamoré de él... Y es tan raro eso: cómo se le va metiendo a uno el amor así: como a escondidas, despacio: como si fuera a doler. Debe ser porque la belleza golpea muy duro, yo creo. De verdad: uno está por ahí tranquilo, y de pronto Leonardo se para enfrente con toda esa hermosura; y uno se queda quieto, sin poder mirar a otro lado: como muerto; y entonces con qué fuerzas hubiera podido yo soportar toda esa felicidad que se viene encima cuando por fin Leonardo se ha echado sobre mi para besarme, si no lo agarrara a uno el amor así de fuerte. Pero así de suave: como si nada. (Molano, 1992, p 150).
Así de fuerte y así de suave son las cosas que el amor reserva para los que lo viven. Sin embargo, lo descrito por Fernando Molano pareciera un bonito relato de ficción, en tanto la vida real vivida por los muchachos en las instituciones educativas dista de ser represiva y, por lo mismo, las instituciones no pretenden regir las consciencias y los afectos de los sujetos a quienes dicen formar, Héctor Abad Faciolince referirá en el prólogo a la tercera edición de Un beso de Dick, de qué está compuesta la reputada sociedad colombiana:

Un beso de Dick circuló muy poco, porque la Cámara de Comercio debía enviar muchos ejemplares de cortesía a muchos mercachifles (algunos se escandalizaron con el premio, y hasta enviaron rigurosas cartas de protesta por las "vulgaridades" del libro) (2005, p. 9).

Héctor Abad Faciolince fue uno de los jurados que otorgó el premio a Fernando Molano, luego la sanción que declaraba la novela como vulgar también recaía sobre su criterio a la hora de acercarse y juzgar una obra. Abad Faciolince, exdirector entonces de la revista de la Universidad de Antioquia y reputado literato, quedaba cuestionado en su criterio ético, literario y estético en torno a lo que se podría publicar y a lo que merecería algún reconocimiento. Pero ¿para qué llamar a engaños? No era el lenguaje franco y cotidiano lo que atormentaba los pulcros ojos de quienes mejor creyeron evaluar/descalificar Un beso de Dick, tampoco la preocupación central era qué tanto el criterio de los jurados comprometía el premio: simple y llanamente lo que ofendía y lo que se constituía en un gesto o ejemplo antiformativo para los jóvenes (y para el lector en general) era que dos muchachos que se aman aparecieran bellamente representados en una obra, inyectando su veneno a una sociedad que entroniza la heterosexualidad como norma, pero que se obsesiona hasta los límites de la fascinación con la homosexualidad. Entonces, no se trataba de los usos del lenguaje, se trataba de conservar el privilegio de la ignorancia, aquel que no se quiere perder estando obligados a aceptar la evidencia del amor de/en- 
tre los muchachos. Así que el amor que no osa decir su nombre, y que así se prefiere para tranquilidad de las consciencias pacatas, renuncia al silencio y se dice... se dice a través de Felipe y Leonardo, héroes que por un momento logran arrebatarle a la formación pedagógico-moral de Colombia el derecho a decirse mediante sus propios términos y a partir de sus propios gestos. Si desde Kant se aseguró que es a través de la educación que el ser humano llega a ser lo que es, entonces la educación tendría que responder por la cadena de exclusiones/marginaciones que produce y perpetua. Dicha cadena establece, con criterio pedagógico, los cuerpos que deben ser ocupados, las opciones vitales disponibles y las vidas que no merecen ser vividas, y que, por lo mismo, deben ser desechadas.

\section{La pedagogía envenenada es una pedagogía transgresora}

Las duchas escolares, ese lugar de encuentro que tanto obsesionó a Wenceslao Montoya y sus propuestas de higiene escolar, al punto de sugerir que la construcción de instituciones educativas acordes a la higiene (¿y a la moral?) debían tener cierto tipo de accesos privilegiados en las duchas, para que los maestros/maestras pudieran irrumpir intempestivamente y observar qué hacen los muchachos en ellas, son un punto privilegiado para pensar la sexualidad en la novela de Fernando Molano. En Un beso de Dick se juega intensamente con la imagen de las duchas para mostrar lo que difícilmente la pedagogía de la normalización ha querido reconocer, o más bien, sobre lo que la pedagogía no ha querido posar sus reflexiones. Aspecto que no es de extrañar, pues la pedagogía, al privilegiar la normalidad, asume la ventaja que la ignorancia proporciona para sancionar a priori lo que se constituye mediante la negación. Se hacen jugar todas las técnicas de la vigilancia y la amenaza de la exclusión contra los que son señalados con la marca de la anormalidad. Una vez más se reactiva el dispositivo disciplinario para enfrentar "la peste". La normalidad se erige sobre la base de un no querer saber cómo los muchachos, si bien pueden resolver su placer, sus pasiones y la posición de sus cuerpos, probablemente contra sí mismos, a medida que van creciendo y adquiriendo madurez, también en ese espacio impredecible de las identificaciones, ocupan una posición estético/ corporal y erótico/sexual que funge desde las prácticas cotidianas mismas y no sólo desde la prescripción pedagógico moral de la normalidad. Al respecto, sígase a los personajes de Fernando Molano, en las duchas:

Algunos comenzaron a desnudarse de prisa para ganar los primeros turnos en las duchas: sólo hay seis chorros en la bañera abierta. Cuando empezaron las disputas ya Leonardo estaba bajo el agua, enjabonándose de espaldas. Tato se le acercó, con la confianza que uno sólo les tiene a los árboles, el muy ladino, y se lo arrimó por detrás, como de pasada:

-Ah, perdón: no me di cuenta -le dijo, y se quedó bajo el chorro.

Leonardo se dio vuelta sin inmutarse, le pasó los ojos de arriba abajo y se quedó mirándosela a Tato (la tenía tan pequeñita por el frío):

-Pobre tipo -dijo como si le diera mucha lástima, y Tato no supo qué responderle en medio de nuestras risas.

Coloso estaba en la ducha de al lado y aprovechó la ocasión (Coloso siempre aprovecha la ocasión):

- ¿Será que esta le sirve, Leonardito? (1992, p 17-18)

A lo mejor muchos estarán tentados a suponer/negar que una escena de este tipo realmente ocurra en una escuela; muchos estarán tentados, con el privilegio de la ignorancia, a decir que dichas cosas no pasan... o que pasan en la mente de pervertidos e inmorales: díscolos muchachos que truncando su naturaleza se observan, se miran y se miden recíprocamente. $\mathrm{O}$ tal vez, dirán, que esas cosas no pasan ni en las mentes de los muchachos, si acaso pasan en las mentes depravadas de sujetos que, sin juicio moral y sin temor de Dios, escriben sobre esas cosas para confundir a los más jóvenes o a las mentes más "dé-

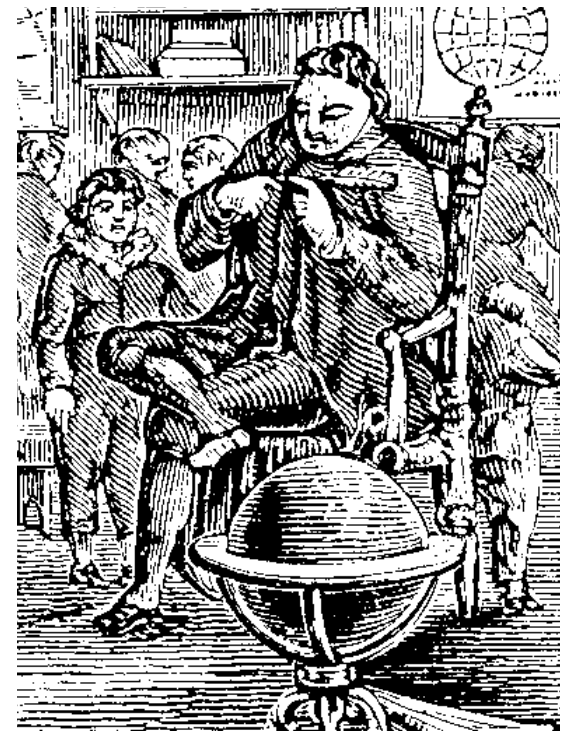

biles" y sugestionables ${ }^{4}$. Sin embargo, Monick (1994) sostiene que los hombres y las mujeres experimentan fascinación por el pene (o su figura simbólica el falo). De hecho, es enfático sugiriendo que los hombres, tal vez, estarían mucho más hechizados por el pene (falo) que las mujeres, porque sobre ese deseo se acarrea mayor sanción social ${ }^{5}$. La manera como ese hechizo se acentúa dependerá entonces de la disposición personal. O de modo similar, la manera como se ocupa una posición corporal y erótica dependerá de las cuestiones que entren en juego dentro de una economía de identificaciones. Si bien en ese juego (léase la escena de las duchas) los

4 Cosa que los discursos religiosos, moralistas, adoctrinantes y, para el caso, la pedagogía con fines universalizantes, jamás harían.

5 Esa sanción social se podría equiparar a lo que Sedgwick (1998) ha nombrado como "pánico homosexual": pánico exacerbado y saturado de vigilancia por temor a la aparición del cuerpo homosexual en la escena cotidiana. Lo paradójico de ese pánico es que sólo puede identificar la aparición de ese cuerpo que repudia a partir de su inevitable relación/proximidad con ese cuerpo. Dicho de otra manera, porque se conoce ese deseo es que se rechaza. De cierto modo, se trata de volver contra sí mismo lo que conociéndose se ha fantaseado como lo propio del otro. 
muchachos se muestran/demuestran virilidad, capacidad de penetrar y exhuberancia corporal con respecto al placer, también se examina como posibilidad. La posibilidad de jugar, con los roces y las miradas, a experimentar/intensificar un placer mal visto, sancionado y del que se preferiría no saber. Schérer dirá que "[...] la sexualidad implica siempre una forma determinada de relaciones sociales y de circunscripción del campo social" (1984, p. 48). De este modo, si los muchachos reproducen estructuras de subordinación y machismo en las duchas ( $y$ en otros juegos que requieren contacto físico), también se puede determinar en esos juegos una posición corporal y erótica no contemplada y no nombrada por el plan natural de la creación que Comenio, por ejemplo, defendía.

Continúese en las duchas: Coloso presumía del tamaño de su pene ofreciéndoselo a Leonardo. Coloso fija su mirada en el trasero de Leonardo para sostener que con un trasero así no tendría que trabajar. Toda la escena se da entre muchachos que, al parecer, se definirán como heterosexuales pero que requieren de dichos juegos para probar/ probarse ensayando la sexualidad de "los otros". Por su parte, Leonardo busca cómo resistir a Coloso, burlarlo y, probablemente, disminuir el aprieto en el que Coloso lo desafía a dar una respuesta ingeniosa. En ese juego, Leonardo alcanza a molestarse (olvidando el juego), y manifiesta su molestia... pero el juego sigue vigente: en un descuido, mientras Leonardo busca su toalla, le son arrebatados sus pantaloncillos blancos (que los muchachos relacionan con la virginidad). Juegan con los pantaloncillos de Leonardo que circulan de un lado a otro, Leonardo se rinde...; mientras tanto, Felipe, que no ha participado y que sólo ha estado observando cómo transcurre ese juego en el que se escenifican posiciones erótico/sexuales y lugares posibles para frecuentar el placer que no necesita identificarse como heterosexual u homosexual, sale de la ducha humedecido:

Cerré la llave y con las manos me sacudía el agua del pelo. Leonardo se había colocado su camisa y le hacía un ademán a Carlos para que se los entregara (los pantaloncillos).

-Tome -le dijo Carlos; pero él me los lanzó a la cara.

¡Y los pantaloncillos de Leonardo se quedaron pegados sobre mi frente húmeda.

En ese instante me reproché, como si fuese mi culpa, la maldita obligación de asquearme con lo que yo más quería: casi maldije mi suerte inútil. Pero ahí mismo recordé, como una revelación de Dios, las bromas de hacía un momento, el juego inocente con todo lo que está prohibido, y me maravillé de las cosas que uno puede esconder bajo las bromas. Entonces tomé los pantaloncillos con mis manos y comencé a secar con ellos mi rostro: despacio, como si lo hiciera con mi pañuelo, como si yo estuviera solo con mi pañuelo. Sentí perfectamente cómo todos se silenciaban mirándome; y todavía me di tiempo para extenderlos sobre mis palmas, llevarlos sobre mi nariz, y aspirar profundo como si fuese un perfume: simulando: como si no fuera el placer que yo sentía.

-¡Chanel! -dije con un suspiro de lo más payaso (Molano, 1992: p. 20).

El juego no acaba allí, Felipe ha propuesto, sin decirlo, unas nuevas condiciones dentro de él, en las cuales todos deben reordenar sus posiciones: él ha intimidado a sus compañeros y ha decidido llevar el juego hasta los límites de lo permitido con un placer difuso. Leonardo "con su cara triste" mira a Felipe mientras ese juego persiste, agacha la cabeza y Felipe parece sentir con ello un desplante, se enoja y le lanza a los pies los pantaloncillos que le eran tan gratos hace un momento. Es como si toda la escenificación/dramatización de Felipe tuviera por objeto hacer que Leonardo lo mire a los ojos y sostenga su mirada. Sin embargo, el desdén de Leonardo (más tarde se sabrá que es más bien una pequeña derrota), enfurece a Felipe tanto como para olvidar que ante los ojos y la mirada de Leonardo, Nastassja Kinski y Bette Davis palidecen. Los muchachos aceptan el nuevo reordenamiento del juego y el juego sigue:

-¡Pero vaya póngaselos, papi! -Me dijo Tato entre dientes.
-Y no se le olvide besarle las güevas...: miren al maricón este!

-Dijo Coloso lanzándome un golpe bajo con su toalla.

A mi me dio sensación de risa y todos vinieron a darme una zurra de toallazos

- ¡Téngamelo ahí, Coloso! -dijo Carlos, y fue a recoger de nuevo los pantaloncillos.

Entre cuatro me sujetaban...

-A ver, a ver niño, cómaselos despacio -me decía Carlos.

En ese instante sonó el timbre y yo sentía a mi boca resecarse con los pantaloncillos de Leonardo: casi lo amo al Carlos. De nuevo, sonó el timbre y todos salieron corriendo. Vi a Coloso llevándose mi maletín y corrí tras él, se había ocultado junto a la puerta y me lo puso de un golpe contra el vientre:

-¡Apúrense, o no los van a dejar entrar a clase! -me gritó mientras corría-. ¡Y sáquese eso de la boca, cochino! (Molano, 1992: p. 20).

Una vez termina el juego, y una vez salen de las duchas, el placer abyecto que logre salir de allí no podrá nombrarse de otra manera que como un placer "cochino". Si los muchachos escenifican posiciones no contempladas, también se retraen. En el juego jugado abandonan posibilidades para el placer que, tal vez, otros muchachos retomarán como su placer mirando a los ojos, de frente, a una sociedad que los sancionará por ello.

¿Qué más agregar al relato de Fernando Molano? ¿Qué más se puede decir, cuando su relato ha hecho proliferar consecuencias pedagógico-formativas no mediadas por el maestro/maestra, no contempladas y harto intensas como para proponer que la escuela, si bien dispositivo de normalización, también es el lugar donde el poder de ese dispositivo puede ser resistido/subvertido? Si Fernando Molano ha producido, sin querer, una pedagogía transgresora, pervertida o queer, no queda más camino que aceptar su incitación y ahondar en su propuesta. Felipe, el personaje de 
la novela sobre quien recae la reflexión de las situaciones, bien ha expuesto que el juego, inocente (con aquellos tabúes que la pedagogía instituye), es la oportunidad para que los muchachos jueguen a la insubordinación, demostrando que la pedagogía, en tanto empresa de normalización, normaliza pero con la condición de una empresa que fracasa negando su precariedad y su incapacidad de contener la emergencia de posiciones estético/corporales y erótico/sexuales que, tal vez, negadas y sancionas por la pedagogía, devienen intensificadas en el espacio escolar. Es decir, la escuela, enfrentando unos placeres descalificados, se constituye en un espacio de "alta saturación sexual" (Foucault, 2002b: p. 61). En una síntesis, si se prefiere fetichista, Dios, las duchas, los pantaloncillos blancos (con los que hasta Jesús es representado en la cruz), un fuego que no da tregua, la humedad y la cercanía de unos cuerpos con otros, la desnudez, los tabúes, el juego y todo lo que puede ser erotizado, devuelven a los muchachos, como posibilidad no predicha, el placer negado/ repudiado 6 .

Britzman (2005), ha acuñado el término "pedagogía queer", para tratar la cuestión problemática y desafiante que surge en la intersección de la pedagogía, el psicoanálisis y la teoría queer ${ }^{7}$. Asume

6 Se podrá decir entonces que habría que clausurar las duchas escolares o reforzar su vigilancia para que éstas no sirvan de intercambios no predestinados. Sin embargo, de nada serviría una opción tan ingenua. El punto sobre el que se viene trabajando expone que la pedagogía, si se asume como proyecto universalizante, sólo lo puede hacer bajo el signo de una precariedad que no logra destituir las formas que los muchachos encuentran para desinstitucionalizarse y refutar las ordenanzas de un ejercicio brutal sobre el cuerpo. En tal caso, si de cerrar espacios se trata, indáguese también cómo hasta las mismas iglesias y sus paredes sirven para la invención de intercambios eróticos entre los muchachos.

7 Queer significa "raro", "extraño", pero también se ha utilizado como designación que devalúa a los homosexuales. a Freud para señalar el vacío en el que se cifra la pedagogía en tanto defiende su compromiso con la normalidad, lo que hace que en muchas de sus versiones las reflexiones pedagógicas no sean capaces de elaborar tentativas para teorizar, analizar e incorporar el conflicto. No se trata meramente de interpretar "el conflicto social", sino de movilizar recursos que desajusten la lógica binaria de lo público/privado, lo normal/anormal, lo masculino/femenino y lo heterosexual/ homosexual. En este sentido, el conflicto está ligado a las distintas posiciones estético/corporales y erótico/sexuales que la pedagogía se niega a reconocer, pero que no por ello dejan de acontecer en los espacios educativos. La misma Britzman dirá que la pedagogía tiende a ignorar el carácter cotidiano de los placeres, las identificaciones y las posiciones corporales, mientras se ocupa de entronizar universales en nombre de su compromiso con la normalidad. De este modo, una pedagogía transgresora, pervertida o queer, intentaría movilizar otros recursos para desestabilizar las prácticas opresivas. Por ejemplo, darle cabida a los objetos denostados por la pedagogía como "lo extraño", haciendo de ellos su causa a defender; producir relaciones y vínculos problemáticos y no canónicos; construir interpretaciones que muestren la tiranía del sentido y su ruptura; preguntar y decir lo que no se quiere responder o escuchar; hacer

Lo que la teoría queer (queer theory) ha hecho se corresponde con el esfuerzo de retomar esas palabras que infringen la injuria, apropiarlas y retornarlas al campo social debilitadas en su poder para ofender a los homosexuales. Se trata, de algún modo, de hacer un ejercicio paródico desmultiplicando los usos y contradiciendo las prácticas interpretativas que regulan las designaciones utilizadas contra los sujetos inferiorizados socialmente. La teoría queer ha luchado contra "la camisa de fuerza" que supone la "institucionalizacion", intentando radicalizar un "ambiguous (un)becomig" como esfuerzo teórico-formativo. Esto ha supuesto la formación como proceso ambiguo: devenir sería desdevenir. Lo que para la pedagogía significa formación es forzosamente deformación. proliferar ambigüedad en las certezas y ocuparse de señalar que las posiciones del sujeto, siendo temporales, se forjan más allá de los arreglos a universales, y en estos últimos sólo encuentran posibilidad de oponerse y/o ajustarse a ellos (cargando como vergüenza la incapacidad de ocupar completamente los lugares que los universales asignan para el sujeto).

Britzman (2005) va a sugerir que el amor es la primera condición para el saber. De hecho, propondrá preguntarse por la verdadera diferencia entre enamorarse de alguien y enamorarse de sus ideas. Sobre esa pregunta intentará forzar a la pedagogía y a las prácticas educativas para que reformulen la posición que quieren ocupar con respecto a la sexualidad. Si amar y enamorarse es la condición para el saber, entonces, ¿qué respuesta puede agenciar la pedagogía para un amor/enamorarse que se da de un estudiante por su maestro/maestra? ¿Qué suscita como reflexión pedagógica, además de la descalificación, el hecho de que un maestro/maestra ame/se enamore de su estudiante? ¿No serían esos amores y esos enamoramientos una posibilidad para que el saber se constituya como saber de algo? Y, ¿qué decir, pedagógicamente e incorporando gestos formativos, frente a los muchachos que se enamoran unos de otros... y que al enamorarse cobra significado para ellos la escuela?

Fernando Molano muestra a Felipe y Leonardo enamorados el uno del otro, ambos, en un principio, con la reserva de aún no saberse correspondidos. Muchas horas se la pasa Felipe pensando qué pasaría si Leonardo supiera que él lo ama. A lo mejor lo golpearía (piensa), pero de seguro no lo avergonzaría porque Leonardo no es así (se dice). Felipe, el personaje sobre el que se ha dicho recae la reflexión, se ha preguntado ¿cómo se enamora uno de otro muchacho?, para responderse retórico: ¿cómo es posible aguantarse la belleza tanta de Leonardo? Fernando Molano dibuja, con su insistencia, unos personajes movidos hacia la escuela y hacia el saber gracias al amor que sienten el uno por el otro (de hecho, Leonardo dirá que el equipo 
de futbol de su escuela no tiene sentido para él si allí no está Felipe). Felipe que no sabía de literatura, ahora disfruta la poesía por su cercanía con Leonardo, Leonardo que no sabía de pintura, ahora amplifica su lectura de la poesía a través del mundo que Felipe le muestra en los libros de pintura. ¿Podría entonces decirse que amar/enamorarse no puede ser el empuje hacia el saber? ¿Puede la pedagogía soportar que el amor por el saber también es un amor erótico/sexual y no por ello denostable?

\section{A MODO DE CONCLUSIÓN: LOS INQUISIDORES CONTRA FELIPE}

En Un beso de Dick circulan distintos lugares de enunciación que se corresponden en la escuela: esos lugares se denominarán inquisidores. En determinado momento Felipe y Leonardo que ya se han declarado mutuamente su amor, son amigos, no son novios (porque según Felipe eso suena "chistoso"). Sin embargo, amigos son de la cama, de los besos furtivos en los parques, en los baños de la escuela y en los andenes de las casas cuando nadie les ve. Amigos son de un sexo que continuamente está renegociando las posiciones de cada uno en la relación y que les plantea los compromisos del amor. Si algo queda claro de todo ello es que Felipe y Leonardo están aprendiendo: ¿no se ha dicho en distintos discursos educativos que lo suyo es la preocupación por el aprendizaje? ¿Cómo se podrían bloquear los prejuicios que descalifican los distintos modos que tienen los muchachos para aprender unos de otros?

Balderston (2006) ha referido sobre Un beso de Dick que los personajes apuestan por una lucha en la que intentan resolver su condición más esencial con respecto al deseo y la defensa de su amor; señalando, probablemente, las fuerzas que los muchachos tienen que enfrentar interiormente cuando se descubren amando a otro muchacho. Más allá de eso, lo que en este trabajo se ha buscado no es exacerbar una búsqueda subjetiva de lo más propio e íntimo, acaso no atravesado por la educación o la cultura: antes bien, se ha tratado de plantear, a partir del cuerpo y el placer, el papel inquisidor que la pedagogía con arreglo a universales y la práctica educativa ejerce sobre los muchachos. El celador, el maestro de álgebra, el maestro de historia, la psicóloga y el sacerdote, son los personajes que Fernando Molano usa/denuncia como los inquisidores que, una vez descubierto Felipe como partícipe de un deseo homoerótico gracias al descuido de sus cuadernos, asientan su marca con una fuerza que vuelve a insistir sobre la necesidad de pedagogizar al muchacho y arrancarlo de las garras del cuerpo homosexual.

Felipe y Leonardo, en una de las tardes en que se besaban en las gradas de la escuela, entre juegos y recuerdos de días en los que soñaban con el amor del otro, se van diciendo cómo se quieren y van poniendo a prueba el significado de los recuerdos que la memoria les da; entre tanto, el celador que los ha visto, va tras ellos mientras les grita: "maricones" (Molano, 1992, p. 95). Los ha visto pero no los conoce; en un descuido, Felipe deja sus cuadernos y huye mientras detrás la voz grita "maricones". Decirle maricón a alguien es injuriarlo, pero mucho más hondo que la misma injuria es el poder que se adjudica quien grita maricones para activar un orden social que sanciona los besos entre dos muchachos, y para establecer que quien hace cumplir ese orden está en una posición privilegiada desde donde puede marginar, excluir o censurar. El celador, que representa la voz de la muchedumbre, no puede decir nada más, no sabe nada más, pero tampoco necesita saber o decir algo más, basta con que desde su lugar pueda hacer persistir la descalificación que se nombra cuando son los otros a quienes se puede tratar como "maricones". El término degradante (marica, raro, volteado, entre otros) actúa como instrumento de cohesión entre los miembros del cuerpo social que lo pronuncian o pueden pronunciarlo. Cohesión que parece gravitar alrededor de un tabú que se quiere evitar/rechazar. Pronunciar el término degradante funciona, en apariencia, como la estrategia con la que se evita el contenido "contagioso" que el término invoca. De alguna manera, el tabú no hace más que recordar la necesidad de rechazar una posibilidad maldita... siempre próxima y que amenaza con "desbaratar" la cohesión del cuerpo social por otra cohesión no heterocentrada.

Ahora bien, si el celador ocupa el lugar de la enunciación que le corresponde a la muchedumbre, qué decir de los maestros de historia y algebra, del sacerdote y de la psicóloga que bien han hecho circular sus sanciones contra todo lo no heterocentrado. El maestro de historia cargará contra el rock, la moda y el pelo largo, de lo que él concluye hay que sospechar posibles tendencias extrañas. El maestro de historia, furioso porque Leonardo no se sabe los nombres de todos los presidentes del Frente Nacional, invita a sospechar, no de una historia política que ha mantenido la desigualdad y la injusticia como una condición universal de Colombia. No. De eso no se trata. Se trata de avergonzar a los muchachos que no saben los nombres de los presidentes del Frente Nacional y se trata de censurar, descalificar y perseguir a esos "raritos", "extraños", que en últimas, son los maricones que la muchedumbre persigue ahora con el beneplácito de las "figuras formativas". La psicóloga, por su parte, en posición de un saber de manual, le dice a Felipe que él está confundido (no podría ser de otra forma). Felipe cuenta cómo la psicóloga niega el cuerpo homosexual decretando que se trata de una situación temporal, en todo caso, una confusión que el tiempo puede sanar. Felipe descalifica a la calificada en psicología a partir de sus palabras, ella le ha dicho que con el tiempo él va a entender su verdadero papel. Él piensa: "¡Tan boba!: como si yo estuviera en una película” ( $p$. 110). Si la psicóloga, con el privilegio epistemológico que algunas (y algunos) se pueden adjudicar como expertos de la vida ajena, emite su juicio negando a Felipe y Leonardo el derecho a que lo suyo sea real, Felipe (para sí mismo) invierte y resiste esa tentativa apuntando que el papel que ella supone debe ocupar no tiene relevancia para él... porque él no va a participar de esa película que ella reproduce en el ridículo papel del experto y que no es más que una reformulación, en términos cientificistas, de viejos prejuicios morales. 
Pero no es suficiente que la historia y la muchedumbre se unan en un pliegue que puede reírse y calificar la vida de un muchacho no heterocentrado. Tampoco es suficiente con que la psicóloga juegue a exponer su saber de experta negando el cuerpo homosexual; no es suficiente porque toda la institución educativa tiene que participar del espectáculo bochornoso que se forma alrededor y contra ese cuerpo. Léase al respecto:

El prefecto me dijo: “¿Por qué anda haciendo esas porquerías, Valencia? ¿Quién es el otro?"; casi lo mato...Y el profe de álgebra: "Pero Valencia, ¿por qué?; si usted es un buen estudiante. Yo no sabía que tuviera ese tipo de problemas": me da risa: los matemáticos andan viendo problemas en todas partes. Son como güevones los matemáticos. Y yo que creía que el de algebra era una lumbrera... ¡ Maldición!: se lo contaron a todos los profes: qué plaga más chismosa... Pero la psicóloga si me mató: "Cuéntame Felipe, ¿por qué lo estabas haciendo? Tranquilízate y dime. Yo soy tu amiga" (Molano, 1992, p. 111).

El sacerdote (prefecto) invocando las porquerías, el de las matemáticas buscando el problema, y la psicóloga que busca saberlo todo con actitud insidiosa (en tanto con la simpatía busca acorralar de manera más eficiente al otro), junto con el celador (la muchedumbre), son para Felipe la representación del espectáculo propio de una plaga chismosa (como él dirá). La escuela, entonces, deviene para un muchacho al que se ha querido formar, la institución que, por excelencia, hace proliferar por doquier como una plaga, todas las marginaciones, exclusiones, descalificaciones, injurias y censuras que un joven no heterosexual debe soportar sobre su cuerpo. Con este paisaje por horizonte, ése es el cuerpo que la pedagogía se toma y hace suyo para ajustarlo a cánones universales y naturales. Fernando Molano tal vez lo ha mostrado mejor sin proponérselo: la escuela como guardiana de valores universales y naturales no podría ser esa guardiana si no ejerce sobre los cuerpos la violencia más insidiosa y deformante que un muchacho pueda experimentar.

\section{BIBLIOGRAFÍA}

Abad Faciolince, H. (2005). "Prólogo". En Un beso de Dick. Bogotá: Istmo, pp. 9-12.

BAlderston, D. (2006). Baladas de la loca alegría: literatura queer en Colombia. En J. Serrano Amaya (ed.). Otros cuerpos, otras sexualidades. Bogotá: Pontificia Universidad Javeriana. Pensar.

BritzmAN, D. P. (2002). La pedagogía transgresora y sus extrañas técnicas. En R. Mérida Jiménez (ed.). Sexualidades transgresoras. Una antología de estudios queer. Barcelona: Icaria, pp. 197-227.

BritzMAN, D. P. (2005). Educación precoz, En S. Talburt y S. R. Steinberg (eds.). Pensando queer. Sexualidad, cultura y educación. Barcelona: Grao, pp. 51-72.

Foucault, M. (2002a). Vigilar y castigar. Nacimiento de la prisión. Argentina: Siglo XXI Editores.
Foucault, M. (2002b). Historia de la sexualidad. vol. I. La voluntad de saber. Argentina: Siglo XXI Editores.

JAmBRINA, J. (2000), Sujetos queer en la Literatura cubana: hacia una (posible) genealogía de la homoerótica, [en línea] disponible en http://alocubano. com/literaturahomoeroticaenCuba.htm. Recuperado el 1 de mayo de 2009.

Molano Vargas, F. (1992). Un beso de Dick. Medellín: Cámara de Comercio de Medellín.

Monick, E. (1994). Phallos. Símbolo sagrado de la masculinidad. Chile: Cuatro Vientos.

Pedraza, S. (1999). En cuerpo y alma. Visiones del progreso y la felicidad. Bogotá: Universidad de Los Andes.

Planella, J. (2006). Cuerpo, cultura y educación. Bilbao: Desclée De Brouwer
Sedgwick, E. K. (1998). Epistemología del armario. Barcelona: La Tempestad.

SEOANE, J. B. (2006). El placer y la norma. Genealogía de la educación sexual en la España contemporánea. Orígenes (1800-1920). Barcelona: Octaedro.

SCHÉRER, R. (1984). La pedagogía pervertida. Barcelona: Laertes.

SCHÉRER, R. (2005). A su disposición. En Foucault, la pedagogía y la educación. Pensar de otro modo. Bogotá: Universidad Pedagógica Nacional y Cooperativa Editorial Magisterio, pp. 251-274.

ScheuerL, H. (1981). Antropología pedagógica. Barcelona: Herder.

Zuluaga, O. (1997). Otra vez Comenio, en Revista Educación y pedagogía. 47, pp. $99-118$. 

9 mestigacianes

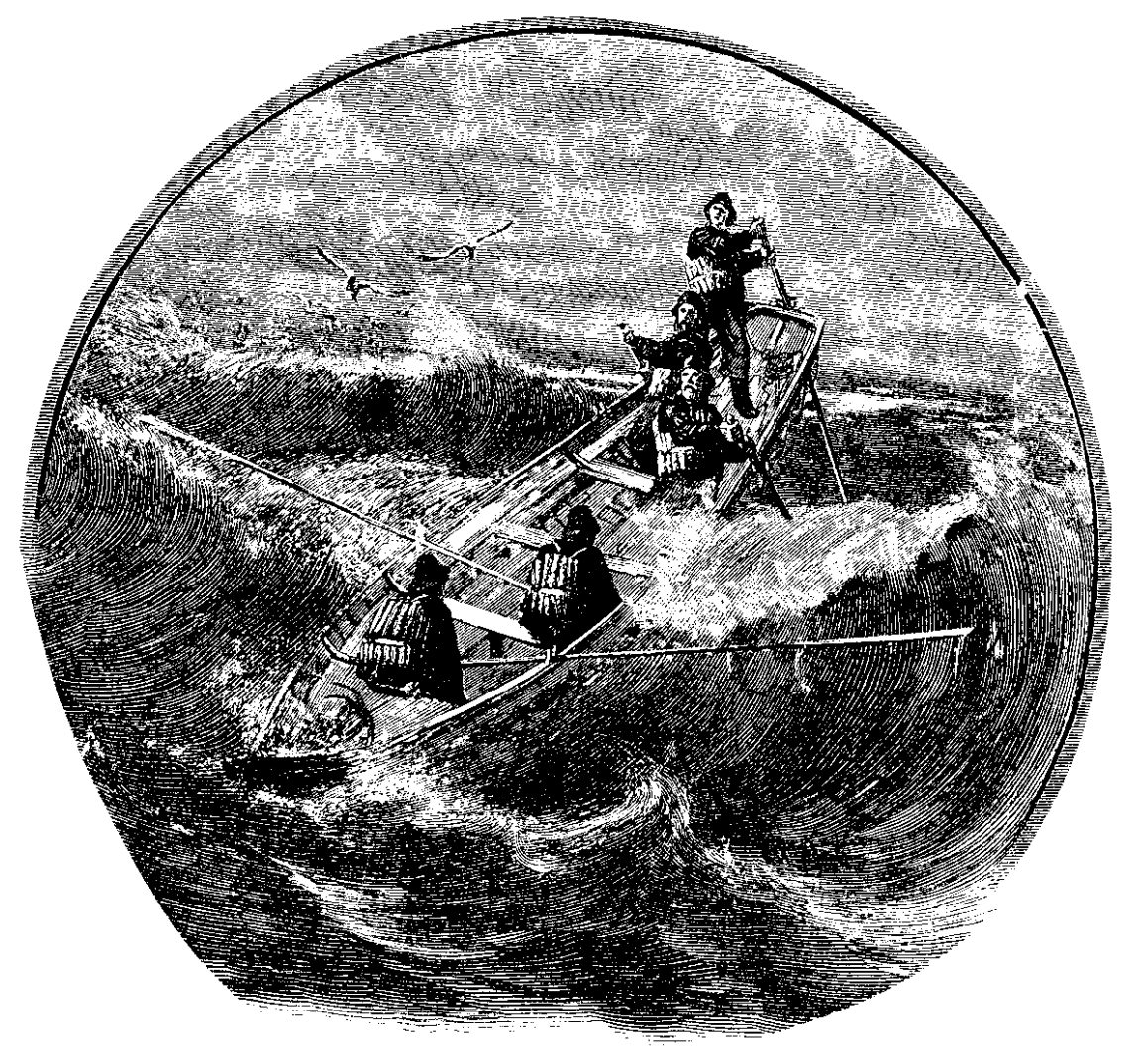



María del Pilar Unda Bernal*

Aroldo Guardiola IBARRA*

Soraya CONSTÁN MEDERO***

OfElia BerRío MORELO*****

MARGARITA MARTíNEZ CAMACHO*****

\section{PEDAGOGÍA, INTERCULTURALIDAD Y FORMACIÓN DE MAESTROS:ESCUELA NORMAL SUPERIOR INDÍGENA DE URIBIA (LA GUAJIRA) ${ }^{\text {watume }}$}

\section{Resumen}

Este artículo resume la investigación realizada sobre un conjunto de prácticas pedagógicas que se realizan actualmente en la Escuela Normal Superior Indígena de Uribia, reconocidas y nombradas como pedagogía de la afirmación cultural por la Expedición Pedagógica. El estudio identifica momentos, características, factores y acontecimientos sociales y políticos relacionados con una forma de hacer escuela que rompe con los propósitos de invisibilización y homogeneización de las culturas, se orienta a la valoración y fortalecimiento de la etnia wayúu y evidencia trazos de un trabajo en perspectiva de interculturalidad.

Palabras clave: Prácticas pedagógicas, diversidad cultural, multiculturalidad, interculturalidad.

* Candidata a Doctora en el Programa de Cultura y Educación en América Latina, de la Escuela Latinoamericana de Postgrados y Políticas Públicas, Elap, de la Universidad de Artes y Ciencias Sociales, Santiago de Chile. Profesora de la Universidad Pedagógica Nacional e integrante del equipo de trabajo coordinador del Movimiento Expedición Pedagógica.Correo electrónico: pilunda@gmail.com

** Magíster en Estudios Político-económicos, Especialista en Planeación Territorial, Licenciado en Lenguas Modernas, Coordinador de la Ruta Afrocaribe de la Expedición Pedagógica, integrante del equipo de coordinación del Movimiento Expedición Pedagógica del Caribe. Correo electrónico: nodocaribe@yahoo.com

*** Licenciada en Etnoeducación y Proyectos Sociales, Especialista en Pedagogía de la Lengua y la Literatura, Maestra de Cultura y Lengua en el Ciclo Complementario, Maestra anfitriona de la Ruta Escuelas Normales Región Caribe Expedición Pedagógica.Correo electrónico: ofebemo@gmail.com

**** Licenciada en Ciencias Naturales, Especialista en Evaluación Escolar, Profesora de Investigación y Coordinadora del Ciclo Complementario de la Ensui, maestra, viajera y anfitriona de la Ruta Escuelas Normales Expedición Pedagógica.Correo electrónico: ofebemo@ gmail.com

${ }^{* * \star * \star}$ Licenciada en Lenguas Modernas, Especialización en Metodología de la enseñanza de la lengua y literatura, Especialización en Orientación Educativa y Desarrollo Humano. Maestra de Teoría Lingüística y de Didáctica de la Lengua en el Ciclo Complementario de la Escuela Normal Superior Indígena de Uribia, expedicionaria anfitriona.Correo electrónico: ofebemo@gmail.com

${ }^{* * * * * \star}$ Este artículo es una síntesis de la investigación financiada por el Fondo Concursable para el Desarrollo de Proyectos de Innovación e Investigación en Educación Inclusiva y Convivencia Democrática, organizado por la Red Innovemos de Unesco, Chile. Una versión ampliada fue publicada en Orealc-Unesco (2008). Educación y diversidad cultural. Lecciones desde la práctica innovadora en América Latina. Santiago de Chile. http://www.redinnovemos.org

Articulo recibido el 16 de abril de 2009 y aprobado el 24 de junio de 2009

Pedagogía y Saberes N.ํㄹㄹ 28. Universidad Pedagógica Nacional. Facultad de Educación, 2008, pp. 113-120 